\title{
Effects of Marine Antagonistic Fungi against Plant Pathogens and Rice Growth Promotion Activity
}

\author{
Tanaporn Chalearmsrimuang ${ }^{1}$, Supaporn Suasa-ard ${ }^{1}$, \\ Arom Jantasorn ${ }^{2}$ and Tida Dethoup ${ }^{1,3 *}$ \\ ${ }^{1}$ Department of Plant Pathology, Faculty of Agriculture, Kasetsart University, Bangkok 10900, Thailand. \\ ${ }^{2}$ Bodhivijjalaya College, Srinakharinwirot University, 114 Sukhumvit 23, Bangkok 10110, Thailand. \\ ${ }^{3}$ Graduate School of Integrated Sciences for Life, Hiroshima University, Kagamiyama, \\ Higashi-Hiroshima, Hiroshima, Japan.
}

\begin{abstract}
Ten marine-derived fungi crude extracts, namely Emericella stellatus KUFA0208, Eupenicillium parvum KUFA0237, Neosartorya siamensis KUFA0514, N. spinosa KUFA 0528, Talaromyces flavus KUFA 0119, $T$. macrosporus KUFA 0135, T. trachyspermus KUFA0304, Trichoderma asperellum KUFA 0559, T. asperellum KUFA 0559 and $T$. harzianum KUFA 0631 were determined for their fungicidal activity against five rice pathogens in vitro. The results showed that the extracts of $E$. stellatus KUFA0208 and $N$. siamensis KUFA0514 exhibited the best antifungal activity, causing complete cessation of the mycelial growth of Alternaria padwickii, Bipalaris oryzae, Fusarium semitectum, Pyricularia oryzae and Rhizoctonia solani at $10 \mathrm{~g} / \mathrm{L}$. The $\mathrm{N}$. siamensis KUFA0514 extract was fractioned and antifungal compounds were found in the fractions derived from petroleum-ether and chloroform (7: 3) evidenced by inhibition zones against the mycelial growth of $A$. padwickii around the disc containing each fraction. Moreover, in rice growth promotion tests, diluted cultural broth of T. asperellum KUFA 0559 and T. harzianum KUFA 0631 were found to strongly promote rice shoot and root elongation; however, higher concentrations of all marine fungal broths resulted in significantly reduced rice seedling growth rather than promotion. Meanwhile, Trichoderma showed great indole-3-acetic acid (IAA) production leading to the optimum IAA values of 45.38 and $52.30 \mu \mathrm{g} / \mathrm{ml}$ at 11 and 13 days after inoculation, respectively. The results of this study indicated that marine fungi are promising agents having antagonistic mechanisms involving antibiosis production and plant growth promotion and may be developed as novel biocontrol agents for rice disease management.
\end{abstract}

Keywords: Antagonist fungi, marine fungi, rice disease control, rice seedling growth

*Correspondence: agrtdd@ku.ac.th; +66 25791026

(Received: November 20, 2021; accepted: January 4, 2022)

Citation: Chalearmsrimuang T, Suasa-ard S, Jantasorn A, Dethoup T. Effects Of Marine Antagonistic Fungi against Plant Pathogens and Rice Growth Promotion Activity. J Pure Appl Microbiol. 2022;16(1):402-418. doi: 10.22207/JPAM.16.1.35

(C) The Author(s) 2022. Open Access. This article is distributed under the terms of the Creative Commons Attribution 4.0 International License which permits unrestricted use, sharing, distribution, and reproduction in any medium, provided you give appropriate credit to the original author(s) and the source, provide a link to the Creative Commons license, and indicate if changes were made. 


\section{INTRODUCTION}

Marine invertebrates are multicellular animals such as sponges, corals and sea fans. Some marine invertebrates can produce a diversity of bioactive compounds that are used in the pharmaceutical and agrochemical industries. ${ }^{1-4}$ Especially, marine sponges are considered as an important source of natural products for cytotoxic, antibiotic and anti-cancer compounds. ${ }^{5-7}$ In addition, marine sponges are the host of various symbiotic microorganisms such as archaic, bacteria, cyanobacteria, fungi and microalgae which are sources of various natural products. ${ }^{8-10}$ Marine-derived fungi can be found in the marine ecosystem growing together with marine invertebrates. Marine fungi can be classified into many groups on the basis of many various criteria; in one such classification, marine fungi are divided into two main groups: obligate marine fungi and facultative marine fungi. ${ }^{11-12}$ The potential uses of the fungi from marine resources as producers of novel antimicrobial metabolites has been reported by numerous studies. ${ }^{13-18}$ Marine-derived fungi isolated from Thailand have been proven to be a great source of novel metabolites and various chemical groups of natural products have been recorded. ${ }^{2,3,19-20}$ Some of these are sources of novel biological control agents against plant pathogenic fungi. ${ }^{21-23}$ In our previous research, we discovered that many potent marine fungi isolated from marine invertebrates possess potential antagonistic activities such as antibiosis production and competition for space and nutrients against important pathogens of economic crops. For instance, Talaromyces tratensis KUFA 0091, which was isolated from the marine sponge, Mycale sp., possessed high potential biological activity in controlling rice pathogens, namely, Alternaria padwickii, Curvularia lunata, Fusarium moniliforme, and Bipolaris oryzae. ${ }^{21,24}$ The ethyl acetate crude extract of $T$. tratensis displayed mycelial inhibition of $B$. oryzae at concentrations increasing from $100 \mathrm{ppm}$ to $10,000 \mathrm{ppm}$, with values ranging from $52.36 \%-100 \%$ inhibition in vitro. ${ }^{21}$ Under field conditions, the application of the spore suspension and its crude extract effected reduction of disease incidence of up to $60 \%{ }^{21,24}$ Moreover, this marine fungus proved to be a potent agent in controlling post-harvest disease stem end rot on mango fruit caused by
Lasiodiplodia theobromae. ${ }^{25}$ Furthermore, many crude extracts isolated from marine fungi isolated from Thai waters showed potent antifungal activity on plant pathogens at $1 \mathrm{~g} / \mathrm{L}$ using dilution plate assays. ${ }^{26}$ In addition, these marine fungi were found able to tolerate salinity at $\mathrm{NaCl}$ concentrations of up to $10 \%$ by increasing osmotic pressure. ${ }^{22,27}$

Moreover, many studies have also reported the efficacy of marine fungi as potent biological control agents in plant disease management in many countries. For instance, Trichoderma strains previously isolated from Mediterranean Psammocinia sp. sponges showed high mycoparasitic potential in reducing dampingoff disease severity on beans caused by Rhizoctonia solani and also induced defense responses in cucumber seedlings in reducing Pseudomonas syringae pv. lachrimans infection. ${ }^{27}$ The culture filtrate of marine $T$. longibrachiatum SFC100166 was found to effectively reduce the severity of rice blast, tomato late blight and gray mold diseases in tomato and rice. ${ }^{28}$ It also produced the bioactive compounds spirosorbicillinol B, bisvertinolone, bisorbicillinol and epoxysorbicillinol, which effectively suppressed the incidence of tomato late blight disease, caused by P. infestans. ${ }^{29}$ Moreover, the direct applications of the marine fungi, $T$. longibrachiatum and T. asperelloides as seed treatments resulted in a greater yield and significant increases in maize growth parameters as well as reduced late wilt disease severity caused by Magnaporthiopsis maydis. ${ }^{30}$

Plant diseases are considered a main constraint in crop production which cause yield losses both qualitatively and quantitatively. Many studies have been made to find effective approaches to plant disease management such as searching for biological control agents and novel fungicides and developing integrated pest management. ${ }^{21,30-32}$ In addition, eco-friendly approaches have been sought to minimize negative effects on humans, animals and the environment. Research and development work is being conducted on soil, plant and marine microbes as biological control agents to replace chemical pesticides. While many marine fungi have been evaluated for their antagonistic activity against plant pathogens, for lots of them there still has been no assessment of their antagonistic 
activity against plant disease control and or their capabilities in plant growth promotion. The main purpose of this study was the evaluation of antagonistic activity of marine-derived fungi against five rice pathogenic fungi in vitro and in planta. The investigation of production of the auxin phytohormone, IAA by marine-derived fungi was conducted to assess the effectiveness of marine-derived fungi culture broth to enhance rice germination. In addition, this study was intended to reveal the hidden antagonistic properties of plant pathogenic fungi and also explore the ability of IAA production of marine-derived fungi leading to the development of novel biological control agents which will serve as alternative fungicides for combating plant diseases. The objectives in this study were: 1 . to evaluate the in vitro antagonistic activity of ten marine-derived fungi against rice pathogens, 2 . to investigate the secondary metabolites from the marine-derived fungus, Neosartorya siamensis KUFA 0514, and 3. to study the effects of marine-derived fungal broths on rice seed germination promoting activity and their IAA production.

\section{METHODS \\ Isolation of fungi from marine sponges}

The sample tissues of the sponge Mycale sp. were collected at Samaesan Island $\left(12^{\circ} 34^{\prime} 36.64^{\prime \prime}\right.$ N 10056'59.69" E), Chonburi province, Thailand, in April 2016 at a depth of 5-10 $\mathrm{m}$. by scuba diving. It was identified by taxonomy analysis by Dr. Sumaitt Putchakarn, Institute of Marine Science, Burapha University, Thailand. The sponge was surface disinfection with $0.01 \%$ sodium hypochlorite solution for $1 \mathrm{~min}$, then washed twice by sterilized seawater, and then let it dried on sterile filter paper. The sponge was cut into small pieces $(5 \times 5 \mathrm{~mm})$ and placed on potato dextrose agar (PDA) medium plate mixed with streptomycin sulfate $(0.1 \%)$ to prevent bacterial contamination, and incubated at $28^{\circ} \mathrm{C}$ for 7 days. The hyphal tips emerging from sponge pieces were individually transferred onto PDA slants and maintained as pure cultures under code KUFA for further identification.

\section{Marine-derived fungi identification}

The identification of the fungi was based on morphological characteristics and molecular analysis as described previously. ${ }^{22}$ The fungal morphological characteristics observed were the colony characteristic and growth, color and texture on malt extract agar and microscopic characteristics found through examination with stereoscopic and light microscopes. The isolated fungi were further identified by molecular techniques. DNA was extracted from young mycelia according to a modified Murray and Thompson method ${ }^{33}$ using universal primer pairs ITS1 and ITS4 for ITS gene amplification. ${ }^{34}$ Their accession numbers are shown in Table 1.

Preparation of the marine-derived fungal extracts

The 10 marine-derived fungi were determined for their antifungal activity against plant pathogenic fungi (Table 1). Each fungus was cultured and extracted their metabolites according to Dethoup et al..$^{21}$ Briefly, they were cultured on PDA plates and incubated for 7 days. For preparing spore suspensions, five mycelial plugs of each fungus were removed of a 7-day-old colony and inoculated in potato dextrose broth (PDB), and then incubated on a rotary shaker at $120 \mathrm{rpm}$ for 7 days. The mycelial suspension of each fungus were inoculated in $1 \mathrm{~L}$ Erlenmeyer flasks, containing 300 $\mathrm{g}$ cooked rice and incubated at room temperature for 1 month, after which $500 \mathrm{~mL}$ of ethyl acetate was filled to each flask and macerated for 7 days. The ethyl acetate solutions were filtered through cheesecloth and then evaporated using a rotary evaporator at $45^{\circ} \mathrm{C}$ and 220 mbar, to obtain a crude ethyl acetate extract of each marine-derived fungus.

In vitro antifungal activity test of marine-derived fungi crude extracts against plant pathogenic fungi

The dilution plate method was used for the evaluation of the in vitro antifungal activity against five rice plant pathogenic fungi, namely, Alternaria padwickii KUFA0011, Bipalaris oryzae KUFA0012, Fusarium semitectum KUFA0013, Pyricularia oryzae KUFA0014 and Rhizoctonia solani KUFA0015 which were kept as culture collection at Department of Plant Pathology, Faculty of Agriculture, Kasetsart University, Bangkok, Thailand. To prepare stock solutions, a gram of each of the crude extracts was dissolved in $1 \mathrm{~mL}$ dimethyl sulfoxide and serially diluted with sterile distilled water. One $\mathrm{mL}$ of each stock solution was added to $9 \mathrm{~mL}$ of warm PDA, mixed, and poured into the Petri dishes to give final 
concentrations of 10,1 and $0.1 \mathrm{~g} / \mathrm{L}$. A mycelial plug of each of the five plant pathogenic fungi was obtained from a 7-day-old colony margin with a sterile steel borer and transferred to a PDA plate containing one of the concentrations of each crude extract. All the Petri dishes were incubated at room temperature for 14 days. A PDA plate void of the fungal crude extract was used as a control. The inhibition levels were calculated using the formula as previously studied. ${ }^{26}$ All treatments were done with five replications and repeated twice.

Fractionation of the crude extract of Neosartorya siamensis KUFA 0514

The crude extract of $N$. siamensis KUFA 0514 showed the best antifungal activity in inhibiting the rice pathogen growth in vitro, thus, it was studied further to identify its bioactive compounds using column chromatography. Forty grams of the extract $40 \mathrm{~g}$ was applied to a silica gel column $(200 \mathrm{~g})$, and eluted with petroleum ether (petrol)-chloroform $\left(\mathrm{CHCl}_{3}\right)$, and $\mathrm{CHCl}_{3}$-acetone, $300-500 \mathrm{~mL} /$ fractions. The fractions were analyzed by analytical TLC and combined, according to their composition, as follows: 1-68 $\mathrm{CHCl}_{3}$-petrol (1:1), 69-195 $\mathrm{CHCl}_{3}$-petrol (7:3), 196-318 $\mathrm{CHCl}_{3}$-petrol (9:1), 319-420 $\mathrm{CHCl}_{3}$-acetone (9:1) and 421-485 $\mathrm{CHCl}_{3}$-acetone (4:1).

In vitro antifungal activity test of fractions of Neosartorya siamensis KUFA 0514 against Alternaria padwickii

The combined fractions obtained from N. siamensis KUFA 0514 extract were diluted with methanol and distilled water to final concentrations of 10,5 and $1 \mathrm{~g} / \mathrm{L}$. The pathogen A. padwickii was cultured on PDA for 10 days and then distilled water was poured on the PDA culture plates and the spores were scraped with a steel needle to obtain a spore suspension. After that, the spore suspension was mixed with warm PDA and poured into a sterile Petri dish. Sterile filter paper $0.5 \mathrm{~cm}$ in size was dipped in the combined fraction at each concentration and placed on the prepared PDA plates mixed with the Alternaria spore suspension with three discs per plate containing 10, 1 and $0.1 \mathrm{~g} / \mathrm{L}$. The inhibition zone around the disc was measured using a vernier caliper at 10 days after inoculation. Each treatment was performed with three replicates. Distilled water and mancozeb at 10,1 and $0.1 \mathrm{~g} / \mathrm{L}$ were used as the negative and positive controls, respectively.
In vitro seed germination promoting activity test of marine-derived fungi in rice

Rice seed germination promotion testing

A modification of the methodology of Bhagobaty and Joshi ${ }^{35}$ was used for evaluating the effects of five marine-derived fungi, namely, Emericella stellatus KUFA0208, Neosartorya siamensis KUFA0514, Neosartorya spinosa KUFA 0528, Trichoderma asperellum KUFA 0559 and Trichoderma harzianum KUFA 0631, on rice seed germination. Each marine-derived fungus was cultured in PDB containing $0.5 \% \mathrm{w} / \mathrm{v} \mathrm{L-tryptophan,}$ and incubated using a rotary shaker at $150 \mathrm{rpm}$ for seven days. Afterward, the fungal culture broth of each fungus was filtered through a 0.2-micron syringe filter and designated as a stock solution of $100 \mathrm{~g} / \mathrm{L} \mathrm{ppm}$ concentration. The stock solution was serially diluted by PDB to five concentrations of $0.001,0.01,0.1,1$ and $10 \mathrm{~g} / \mathrm{L}$. Rice seed variety KMDL 105 was surface-disinfected by soaking in $3 \%$ sodium hypochlorite solution for $3 \mathrm{~min}$ and then washed three times in sterile distilled water. The treated rice was then soaked in a crude fungal culture broth in each concentration for twentyfour hours. Rice seeds were placed on wet filter paper in a sterile Petri dish and incubated at room temperature for four days. Rice seed soaked in PDB was used as the control. The shoot and root elongation lengths were assessed after 24, 48, 72 and 96 hours. Each treatment was performed with three replicates.

Determination of IAA production by marinederived fungi

The determination of IAA production by marine-derived fungi was conducted following the method of Bhagobaty and Joshi. ${ }^{35}$ Five marine-derived fungi, namely, Emericella stellatus KUFA0208, Neosartorya siamensis KUFA0514, Neosartorya spinosa KUFA 0528, Trichoderma asperellum KUFA 0559 and Trichoderma harzianum KUFA 0631 were cultured in $200 \mathrm{ml}$ of PDB with $0.5 \% \mathrm{w} / \mathrm{v} \mathrm{L-tryptophan,} \mathrm{and} \mathrm{then} \mathrm{incubated} \mathrm{with} \mathrm{a}$ rotary shaker at $150 \mathrm{rpm}$ at room temperature for twenty-four hours. One $\mathrm{mL}$ of culture broth of each marine-derived fungus was transferred to a $1.5 \mathrm{ml}$ microfuge tube and centrifuged at $13,000 \mathrm{rpm}$ for five minutes. The supernatants were mixed with 4 $\mathrm{ml}$ of Salkowshi's reagent $150 \mathrm{~mL}$ of concentrated $\mathrm{H}_{2} \mathrm{SO}_{4}, 250 \mathrm{ml}$ of distilled water, $7.5 \mathrm{ml}$ of $0.5 \mathrm{M}$ $\mathrm{FeCl}_{3} \cdot 6 \mathrm{H}_{2} \mathrm{O}$ ) and stored at room temperature for 
$20 \mathrm{~min}$. before analysis of absorbance at $535 \mathrm{~nm}$. The concentration of IAA was then analyzed by comparison with a standard curve. An assessment was conducted every day for two weeks. Each treatment was performed with three replicates.

\section{Statistical analysis}

All experiments were carried out twice. Data were statistically analyzed by one-way analysis of variance (ANOVA) and the means were calculated with Duncan's multiple range test $(p<$ 0.05 ), using the statistical program SPSS v.19 (IBM Corporation, Somers, NY).

\section{RESULTS}

In vitro antifungal activity test of marine-derived fungi crude extracts against plant pathogenic fungi

The results of evaluation of the antifungal activity of ten marine-derived fungi crude ethyl acetate extracts against the five rice pathogens revealed that the crude extracts displayed increasing effect against plant pathogens in a dose-dependent manner (Table 1). At the highest dose tested, $10 \mathrm{~g} / \mathrm{L}$, all fungal extracts except Eupenicillium parvum KUFA0237 and Talaromyces macrosporus KUFA0135 extracts displayed complete mycelial growth inhibition of at least one of the plant pathogens tested while the extract of $E$. parvum KUFA0237 exhibited the lowest activity. Neosartorya siamensis KUFA0514 crude extract exhibited the greatest antifungal activity, causing $100 \%$ mycelial growth inhibition against all tested plant pathogens at $10 \mathrm{~g} / \mathrm{L}$ except Fusarium semicteactum and also exerted effective antifungal activity in mycelium growth inhibition of Alternaria padwickii, Fusarium semicteactum and Pyricularia oryzae at $1 \mathrm{~g} / \mathrm{L}$ (Table 1, Fig. 1).

Alternaria padwickii was the most sensitive to the marine fungal extracts; the extracts of Emericella stellatus KUFA0208, Neosartorya siamensis KUFA0514, N. spinosa KUFA0528, Talaromyces flavus KUFA0119, T. trachyspermus KUFA0304 and Trichoderma harzianum KUFA 0631 exhibited $100 \%$ mycelial inhibition of this fungus at $10 \mathrm{~g} / \mathrm{L}$. Meanwhile, the extracts of $E$. stellatus KUFA0208, N. siamensis KUFA0514, $T$. trachyspermus KUFA0304, Trichoderma asperellum KUFA 0559 and T. harzianum KUFA 0631 exerted the complete mycelial growth inhibition of $B$. oryzae at the highest dose tested while E. stellatus
KUFA0208 and N. siamensis KUFA0514 showed significant antifungal activity against the pathogen of 55 and $52 \%$, respectively, at $1 \mathrm{~g} / \mathrm{L}$.

The extracts of $E$. stellatus KUFA0208, N. spinosa KUFA0528 and T. flavus KUFA0119 caused $100 \%$ mycelial growth inhibition of Fusarium semicteactum whereas the extracts of both marine Neosartorya spp. exhibited complete mycelial growth inhibition of $P$. oryzae at $10 \mathrm{~g} / \mathrm{L}$. Furthermore, N. siamensis KUFA0514 extract displayed a promising antifungal effect against the mycelial growth of $F$. semicteactum and $P$. oryzae causing $48 \%$ inhibition at $1 \mathrm{~g} / \mathrm{L}$. In addition, $E$. stellatus KUFA0208, N. siamensis KUFA0514, $T$. flavus KUFA0119, T. trachyspermus KUFA0304 and T. harzianum KUFA 0631 exhibited 100\% mycelial inhibition of $R$. solani at $10 \mathrm{~g} / \mathrm{L}$ but all fungal extracts showed low antifungal activity against this pathogen at low concentrations (Table 1).

Antifungal activity of $N$. siamensis KUFA 0514 fractions against Alternaria padwickii

The total of 525 fractions were collected from the crude extract of Neosartorya siamensis KUFA 0514 through column chromatography as follows: Fr. 1-68 $\mathrm{CHCl}_{3}$-petrol (1:1), 69-195 $\mathrm{CHCl}_{3}$ petrol (7:3), 196-318 $\mathrm{CHCl}_{3}$-petrol (9:1), 319-420 $\mathrm{CHCl}_{3}$-acetone (9:1), 421-484 $\mathrm{CHCl}_{3}$-acetone (4:1) and 486-525 $\mathrm{CHCl}_{3}$-acetone (1:9). They were further analyzed by analytical TLC and combined according to their composition to $\mathrm{A} 1-\mathrm{A} 30$ and then their antifungal activities were evaluated using a paper disc method as shown in Fig. 2. The results showed that the fractions of A8-A14 and $A 16$ derived from combined fractions 69-74, $75-84,85-88,89-93,94-98,99-118,119-162$, and 179-195, respectively, exhibited inhibition zones against the mycelial growth of $A$. padwickii at 5 and $10 \mathrm{~g} / \mathrm{L}$ (Fig. 2). Clear inhibition zones were observed in treatments A8-A14 and A16 of 1.87, $1.70,2.00,1.60,1.47,1.33,0.40$ and $1.23 \mathrm{~cm}$ at 5 g/ $L$ and $2.4,2.2,2.2,2.00,1.9,1.7,1.27$ and 1.27 $\mathrm{cm}$ at $10 \mathrm{~g} / \mathrm{L}$, respectively. However, the fractions showed no activity at the low concentration of 1 $\mathrm{g} / \mathrm{L}$ whereas the mancozeb caused clear inhibition zones of $2.1,1.8$ and $1.2 \mathrm{~cm}$ at 10,5 and $1 \mathrm{~g} / \mathrm{L}$, respectively.

Effects of marine-derived fungi culture broth on rice seed germination

The culture broths of Emericella stellatus KUFA0208, Neosartorya siamensis KUFA0514, 


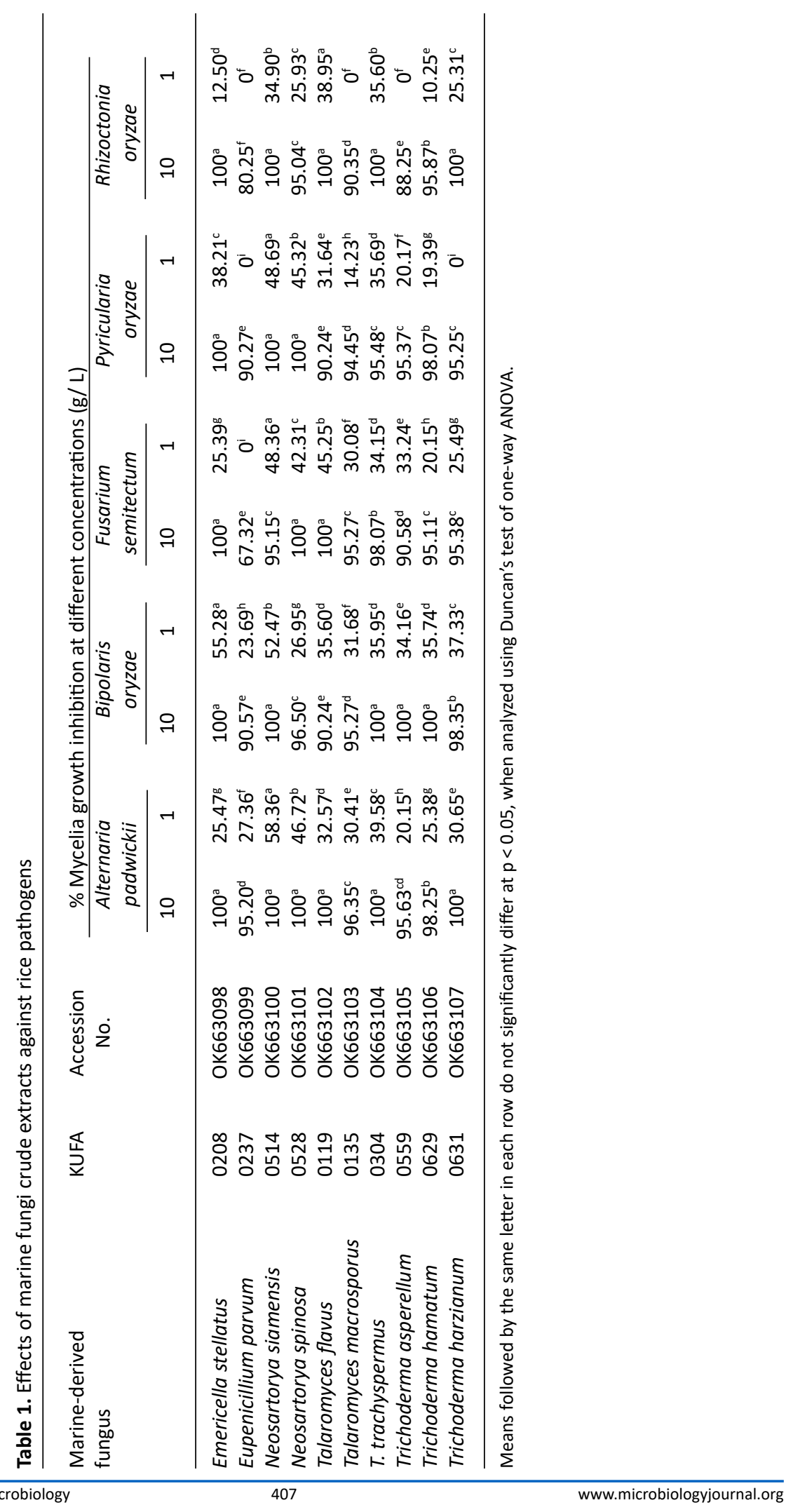


Neosartorya spinosa KUFA 0528, Trichoderma asperellum KUFA 0559 and T. harzianum KUFA 0631 were selected and their rice seed germination promoting activities were tested at $0.001,0.01$, $0.1,1,10$ and $100 \mathrm{~g} / \mathrm{L}$. The results showed that the culture broths of all tested marine-derived fungi stimulated rice germination after $48 \mathrm{hr}$. of incubation (Tables 2-7). However, the rice growth parameter values of both rice root elongation and rice shoot height dramatically increased at the low concentrations of 0.001 to $1 \mathrm{~g} / \mathrm{L}$, but at the concentrations of 10 and $100 \mathrm{~g} / \mathrm{L}$, all fungal broths significantly reduced rice seedling growth rather than promoting it. At $48 \mathrm{hr}$. after inoculation, Trichoderma strains showed potent activity on rice growth, the T. asperellum KUFA 0559 broth at $1 \mathrm{~g} /$ $L$ resulted in the best rice shoot height of $0.47 \mathrm{~cm}$ whereas T. harzianum KUFA 0631 broth caused a shoot height of $0.45 \mathrm{~cm}$ at the same concentration. Meanwhile, T. asperellum KUFA 0559 broth at the low concentrations of 0.01 and $0.001 \mathrm{~g} / \mathrm{L}$ exhibited great stimulation of rice root elongation to lengths of 1.21 and $0.97 \mathrm{~cm}$, respectively (Tables 2-3, Fig. 3).

After 72 hr. of incubation, the culture broths of both Trichoderma also displayed significant enhancement of rice seedling growth, the treatment with T. asperellum KUFA 0559 broth at $0.1 \mathrm{~g} / \mathrm{L}$ displayed the best promotion of rice growth activity causing the greatest rice growth of 0.76 and $1.96 \mathrm{~cm}$ of rice shoot height and root elongation, respectively (Tables 4-5, Fig. 3). Corresponding with the results at 48 and 72 hr., after $96 \mathrm{hr}$. of incubation, the treatment with T. asperellum KUFA 0559 broth at $1 \mathrm{~g} / \mathrm{L}$ resulted in the best rice growth promotion causing the greatest rice shoot height of $1.19 \mathrm{~cm}$ and inducing the best root elongation of $2.49 \mathrm{~cm}$ at $0.1 \mathrm{~g} / \mathrm{L}$ (Tables 6-7, Fig. 3).

\section{IAA production by the marine-derived fungi}

The Emericella stellatus KUFA0208, Neosartorya siamensis KUFA0514, Neosartorya spinosa KUFA 0528, Trichoderma asperellum KUFA 0559 and Trichoderma harzianum KUFA 0631 were evaluated for their IAA production. The IAA production was observed every day during a fourteen-day incubation. The IAA production of all the marine fungi dramatically increased from day 1 to 9 , and the maximum IAA production was observed after 10-12 days of incubation, and then following this, production dramatically decreased. However, the results indicate that $T$. asperellum KUFA 0559 and T. harzianum KUFA 0631 displayed great IAA production leading to IAA concentrations of 45.38 and $52.30 \mu \mathrm{g} / \mathrm{ml}$ after 11 and 13 days of incubation, respectively (Figs. 4-5). Neosartorya siamensis KUFA0514 exhibited moderate IAA production with produced the highest IAA value of $29.78 \mu \mathrm{g} / \mathrm{mL}$ after 10 days of incubation (Fig. 6) whereas E. stellatus KUFA0208 and N. spinosa KUFA 0528 showed low IAA production, with maximum production of IAA only 21.39 and $20.99 \mu \mathrm{g} / \mathrm{mL}$, after 10 and 11 days of incubation, respectively (Fig. 7-8).

\section{DISCUSSION}

The antagonist fungi bring various antagonistic mechanisms to bear against plant pathogens including mycoparasitism, antibiosis production, plant growth promotion and competition for space and nutrients. In this study, we evaluated the antibiosis production of marine

Table 2. Effects of the culture broths of five species of marine-derived fungi at different concentrations on promotion of rice shoot elongation after 48 hours

\begin{tabular}{lccccccc}
\hline \multirow{2}{*}{ Treatment } & \multicolumn{7}{c}{ Shoot length $(\mathrm{cm})$ at concentrations $(\mathrm{g} / \mathrm{L})$} \\
\cline { 2 - 7 } & 0 & 0.001 & 0.01 & 0.1 & 1 & 10 & 100 \\
\hline Emericella stellatus KUFA 0208 & - & $0.15^{\mathrm{kl}}$ & $0.14^{\mathrm{l}}$ & $0.15^{\mathrm{kl}}$ & $0.14^{\mathrm{l}}$ & $0.12^{\mathrm{m}}$ & $0.10^{\mathrm{n}}$ \\
Neosartorya siamensis KUFA 0514 & - & $0.24^{\mathrm{i}}$ & $0.25^{\mathrm{hi}}$ & $0.26^{\mathrm{gh}}$ & $0.42^{\mathrm{c}}$ & $0.37^{\mathrm{d}}$ & $0.34^{\mathrm{e}}$ \\
Neosartorya spinosa KUFA 0528 & - & $0.15^{\mathrm{kl}}$ & $0.10^{\mathrm{n}}$ & $0.12^{\mathrm{m}}$ & $0.08^{\circ}$ & $0.16^{\mathrm{k}}$ & $0.12^{\mathrm{m}}$ \\
Trichoderma asperellum KUFA 0559 & - & $0.11^{\mathrm{mn}}$ & $0.21^{\mathrm{j}}$ & $0.42^{\mathrm{c}}$ & $0.47^{\mathrm{a}}$ & $0.28^{\mathrm{f}}$ & $0.27^{\mathrm{fg}}$ \\
Trichoderma harzianum KUFA 0631 & - & $0.24^{\mathrm{i}}$ & $0.46^{\mathrm{ab}}$ & $0.38^{\mathrm{d}}$ & $0.45^{\mathrm{b}}$ & $0.42^{\mathrm{c}}$ & $0.27^{\mathrm{fg}}$ \\
Negative control & $0.16^{\mathrm{k}}$ & - & - & - & - & - & - \\
\hline
\end{tabular}

Means followed by the same letter are not significantly different at $P<0.05$, when analyzed using Duncan's test of one way ANOVA. 


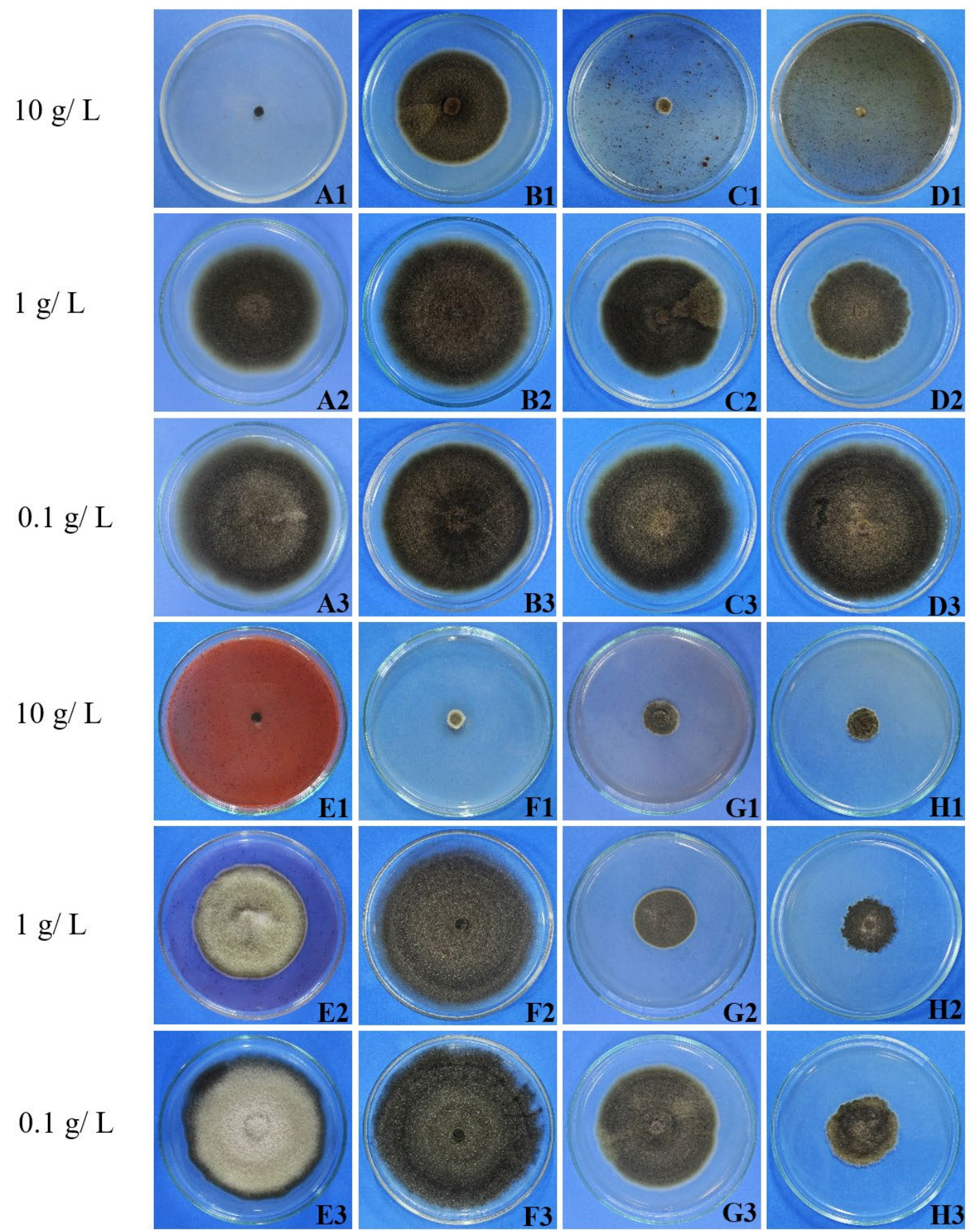

Fig. 1. Effects of marine fungal crude extracts against the mycelial growth of Alternaria padwickii at 101 and 0.1 $\mathrm{g} / \mathrm{L}$ by using the dilution plate method

$$
\begin{aligned}
& \text { A1-A3 }=\text { Trichoderma asperellum KUFA } 0559 \\
& \text { C1-C3 = Trichoderma harzianum KUFA } 0631 \\
& \text { E1-E3 = Emericella stellatus KUFA0208 } \\
& \text { G1-G3 }=\text { N. spinosa KUFA } 0528
\end{aligned}
$$

B2-B3 = Trichoderma asperellum KUFA 0559

D1-D3 = Talaromyces trachyspermus KUFA0304

F1-F3 = Talaromyces flavus KUFA 0119

$\mathrm{H} 1-\mathrm{H} 3=$ Neosartorya siamensis KUFA0514 
fungi on five rice pathogens and determined their rice growth promotion and IAA production in vitro and in vivo. In the antibiosis production tests, the extracts of $N$. siamensis KUFA0514 and E. stellatus KUFA0208 exerted great antifungal activity, causing $100 \%$ mycelial growth inhibition against almost all of the tested plant pathogens at $10 \mathrm{~g} / \mathrm{L}$ whereas E. parvum KUFA0237 extract showed the lowest antifungal activity against the tested pathogens even at the highest dose. At the low concentration of $1 \mathrm{~g} / \mathrm{L}$, the all tested crude fungal extracts showed low activity in inhibition of mycelial growth on all rice pathogens. However, the $N$. siamensis KUFA0514 displayed
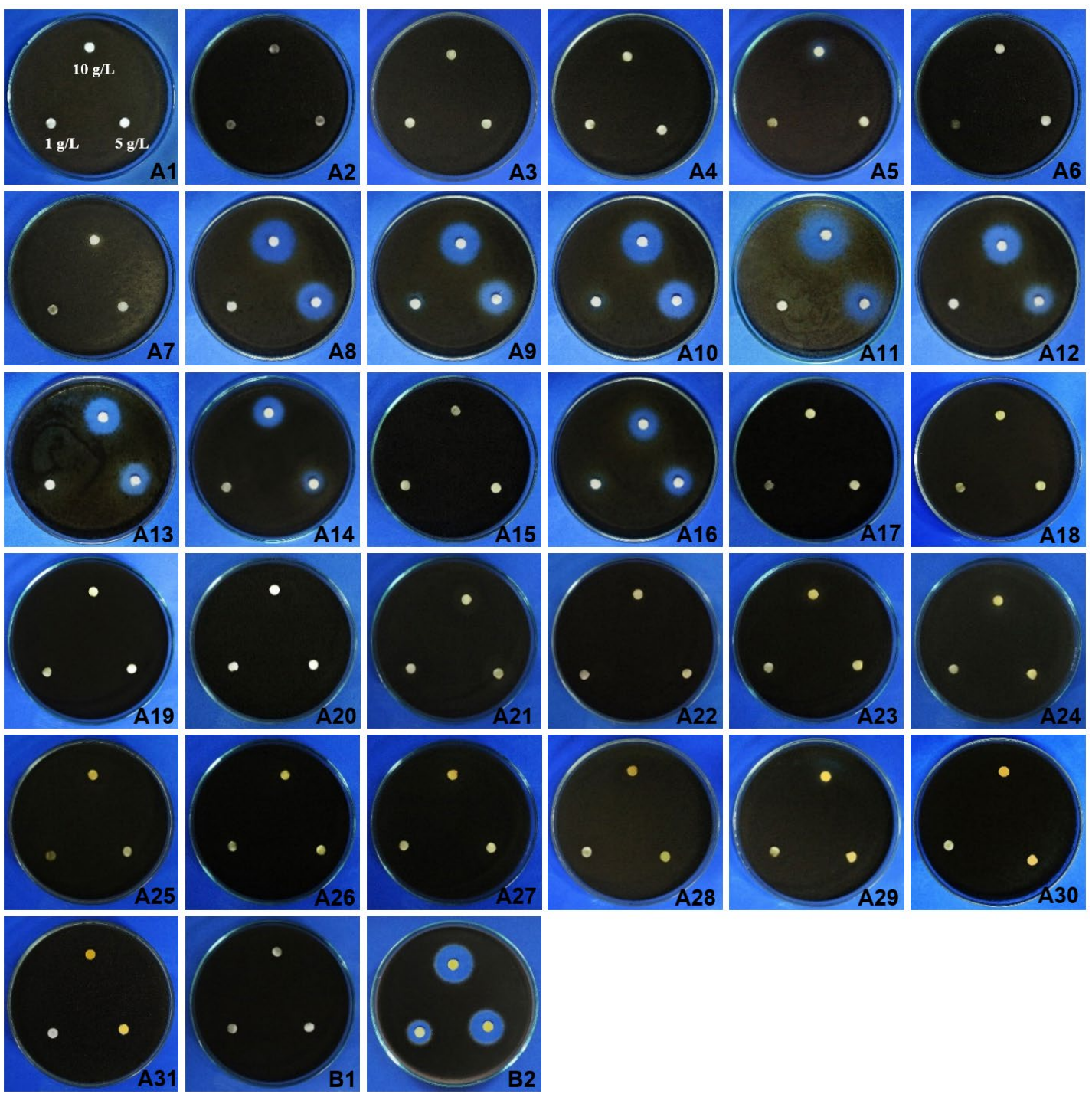

Fig. 2. Effects of fractions obtained from Neosartorya siamensis KUFA 0017 crude extracts of 1,5 , and $10 \mathrm{~g} / \mathrm{L}$ against A. padwickii compared with controls.

A1-A6 = fractions 1-25, 26-35, 35-45, 46-50, 51-56 and 57-61

A7-A12 = fractions 62-68, 69-74, 75-84, 85-88, 89-93 and 94-98

A13-A18 = fractions 99-118, 119-162, 163-178, 179-195, 196-203 and 204-318

A19-A24 = fractions 212-222, 223-239, 240-318, 319-360, 361-382 and 383-405

A25-A30 = fractions 406-409, 410-420, 421-446, 447-460, 461-480 and 481-484

$\mathrm{A} 31$ = fraction 485-525 B1 = negative control (water) B2 = positive control (mancozeb) 
Table 3. Effects of the culture broths of five species of marine-derived fungi at different concentrations on promotion of rice root elongation after 48 hours

\begin{tabular}{lccccccc}
\hline \multirow{2}{*}{ Treatment } & \multicolumn{7}{c}{ Root length $(\mathrm{cm})$ at concentrations (g/ L) } \\
\cline { 2 - 8 } & 0 & 0.001 & 0.01 & 0.1 & 1 & 10 & 100 \\
\hline Emericella stellatus KUFA 0208 & - & $0.43^{\mathrm{l}}$ & $0.51^{\mathrm{i}}$ & $0.30^{\mathrm{p}}$ & $0.67^{\mathrm{e}}$ & $0.09^{\mathrm{u}}$ & $0.02^{\mathrm{w}}$ \\
Neosartorya siamensis KUFA 0514 & - & $0.60^{\mathrm{f}}$ & $0.56^{\mathrm{g}}$ & $0.53^{\mathrm{h}}$ & $0.49^{\mathrm{j}}$ & $0.20^{\mathrm{r}}$ & $0.10^{\mathrm{u}}$ \\
Neosartorya spinosa KUFA 0528 & - & $0.38^{\mathrm{n}}$ & $0.10^{\mathrm{u}}$ & $0.10^{\mathrm{u}}$ & $0.24^{\mathrm{q}}$ & $0.12^{\mathrm{t}}$ & $0.07^{\mathrm{v}}$ \\
Trichoderma asperellum KUFA 0559 & - & $0.97^{\mathrm{b}}$ & $1.21^{\mathrm{a}}$ & $0.17^{\mathrm{s}}$ & $0.41^{\mathrm{m}}$ & $0.00^{\mathrm{x}}$ & $0.00^{\mathrm{x}}$ \\
Trichoderma harzianum KUFA 0631 & - & $0.68^{\mathrm{e}}$ & $0.85^{\mathrm{c}}$ & $0.83^{\mathrm{d}}$ & $0.46^{\mathrm{k}}$ & $0.33^{\circ}$ & $0.00^{\mathrm{x}}$ \\
Negative control & $0.31^{\mathrm{p}}$ & - & - & - & - & - & -
\end{tabular}

Means followed by the same letter are not significantly different at $P<0.05$, when analyzed using Duncan's test of one way ANOVA.

Table 4. Effects of the culture broths of five species of marine-derived fungi at different concentrations on promotion of rice shoot elongation after 72 hours

\begin{tabular}{lccccccc}
\hline \multirow{2}{*}{ Treatment } & \multicolumn{7}{c}{ Root length $(\mathrm{cm})$ at concentrations (g/ L) } \\
\cline { 2 - 8 } & 0 & 0.001 & 0.01 & 0.1 & 1 & 10 & 100 \\
\hline Emericella stellatus KUFA 0208 & - & $0.48^{\mathrm{j}}$ & $0.48^{\mathrm{j}}$ & $0.58^{\mathrm{f}}$ & $0.30^{\mathrm{p}}$ & $0.65^{\mathrm{d}}$ & $0.53^{\mathrm{gh}}$ \\
Neosartorya siamensis KUFA 0514 & - & $0.34^{\circ}$ & $0.40^{\mathrm{m}}$ & $0.40^{\mathrm{m}}$ & $0.42^{\mathrm{l}}$ & $0.64^{\mathrm{d}}$ & $0.24^{\mathrm{a}}$ \\
Neosartorya spinosa KUFA 0528 & - & $0.62^{\mathrm{e}}$ & $0.34^{\circ}$ & $0.58^{\mathrm{f}}$ & $0.35^{\circ}$ & $0.67^{\mathrm{c}}$ & $0.54^{\mathrm{g}}$ \\
Trichoderma asperellum KUFA 0559 & - & $0.30^{\mathrm{p}}$ & $0.73^{\mathrm{b}}$ & $0.76^{\mathrm{a}}$ & $0.50^{\mathrm{i}}$ & $0.47^{\mathrm{j}}$ & $0.37^{\mathrm{n}}$ \\
Trichoderma harzianum KUFA 0631 & - & $0.40^{\mathrm{m}}$ & $0.59^{\mathrm{f}}$ & $0.77^{\mathrm{a}}$ & $0.47^{\mathrm{j}}$ & $0.52^{\mathrm{h}}$ & $0.38^{\mathrm{n}}$ \\
Negative control & $0.44^{\mathrm{k}}$ & - & - & - & - & - & - \\
\hline
\end{tabular}

Means followed by the same letter are not significantly different at $\mathrm{P}<0.05$, when analyzed using Duncan's test of one way ANOVA.

Table 5. Effects of the culture broths of five species of marine-derived fungi at different concentrations on promotion of rice root elongation after 72 hours

\begin{tabular}{lccccccc}
\hline \multirow{2}{*}{ Treatment } & \multicolumn{7}{c}{ Root length (cm) at concentrations (g/ L) } \\
\cline { 2 - 7 } & 0 & 0.001 & 0.01 & 0.1 & 1 & 10 & 100 \\
\hline Emericella stellatus KUFA 0208 & - & $1.67^{\mathrm{e}}$ & $1.56^{\mathrm{f}}$ & $1.19^{\mathrm{h}}$ & $1.86^{\mathrm{c}}$ & $0.20^{\mathrm{s}}$ & $0.09^{\mathrm{v}}$ \\
Neosartorya siamensis KUFA 0514 & - & $1.03^{\mathrm{k}}$ & $1.00^{\mathrm{l}}$ & $0.39^{\mathrm{p}}$ & $1.06^{\mathrm{j}}$ & $0.00^{\mathrm{w}}$ & $0.00^{\mathrm{w}}$ \\
Neosartorya spinosa KUFA 0528 & - & $1.10^{\mathrm{i}}$ & $1.00^{\mathrm{l}}$ & $1.00^{\mathrm{l}}$ & $0.22^{\mathrm{r}}$ & $0.23^{\mathrm{r}}$ & $0.12^{\mathrm{u}}$ \\
Trichoderma asperellum KUFA 0559 & - & $1.83^{\mathrm{d}} 1$ & $0.92^{\mathrm{b}}$ & $1.96^{\mathrm{a}}$ & $1.56^{\mathrm{f}}$ & $0.79^{\mathrm{m}}$ & $0.17^{\mathrm{t}}$ \\
Trichoderma harzianum KUFA 0631 & - & $0.69^{\mathrm{n}}$ & $1.04^{\mathrm{k}}$ & $1.07^{\mathrm{j}}$ & $0.59^{\circ}$ & $0.36^{\mathrm{a}}$ & $0.00^{\mathrm{w}}$ \\
Negative control & $1.23^{\mathrm{g}}$ & - & - & - & - & - & - \\
\hline
\end{tabular}

Means followed by the same letter are not significantly different at $P<0.05$, when analyzed using Duncan's test of one way ANOVA.

significant antagonistic activity against the mycelial growth of $A$. padwickii and B. oryzae by 58 and $52 \%$, respectively. However, to the best of our knowledge, there are no reports of antagonistic activity of this fungus against plant diseases. This fungus was reported as a new species from soils in Thailand ${ }^{36}$ and then its secondary metabolites were identified. The seven new indole alkaloids and 4-dihydroxy-3-methylacetophenone, tryptoquivaline, tryptoquivalines $L, H, F$ as well as fiscalins $A$ and $C$ were isolated from the culture of the fungus Neosartorya siamensis KUFC 6349.37 The chevalone $C$, nortryptoquivaline, fiscalin $A$, epi-fiscalin A and, epi-neofiscalin A were able to cause significant cell death by inducing significant DNA damage and displayed an interesting antiproliferative activity and cell death induction, which may lead to their use as chemotherapeutic agents. ${ }^{38}$ In this study, we found that the fractions obtained from elution with petroleum ether mixed 
Table 6. Effects of the culture broths of five species of marine-derived fungi at different concentrations on promotion of rice shoot elongation after 96 hours

\begin{tabular}{lccccccc}
\hline \multirow{2}{*}{ Treatment } & \multicolumn{7}{c}{ Root length $(\mathrm{cm})$ at concentrations $(\mathrm{g} / \mathrm{L})$} \\
\cline { 2 - 8 } & 0 & 0.001 & 0.01 & 0.1 & 1 & 10 & 100 \\
\hline Emericella stellatus KUFA 0208 & - & $0.82^{\mathrm{k}}$ & $0.96^{\mathrm{i}}$ & $0.99^{\mathrm{gh}}$ & $0.51^{\mathrm{u}}$ & $1.00^{\mathrm{fg}}$ & $1.01^{\mathrm{f}}$ \\
Neosartorya siamensis KUFA 0514 & - & $0.47^{\mathrm{w}}$ & $0.35^{\mathrm{x}}$ & $0.71^{\mathrm{p}}$ & $0.75^{\mathrm{no}}$ & $0.81^{\mathrm{kl}}$ & $0.59^{\mathrm{s}}$ \\
Neosartorya spinosa KUFA 0528 & - & $0.64^{\mathrm{r}}$ & $0.64^{\mathrm{r}}$ & $0.76^{\mathrm{n}}$ & $0.78^{\mathrm{m}}$ & $0.98^{\mathrm{h}}$ & $0.67^{\mathrm{q}}$ \\
Trichoderma asperellum KUFA 0559 & - & $1.12^{\mathrm{d}}$ & $0.56^{\mathrm{t}}$ & $1.17^{\mathrm{b}}$ & $1.19^{\mathrm{a}}$ & $1.03^{\mathrm{e}}$ & $0.71^{\mathrm{p}}$ \\
Trichoderma harzianum KUFA 0631 & - & $0.55^{\mathrm{t}}$ & $0.74^{\circ}$ & $1.15^{\mathrm{c}}$ & $0.80^{\mathrm{l}}$ & $0.84^{\mathrm{j}}$ & $0.49^{\mathrm{v}}$ \\
Negative control & $0.96^{\mathrm{i}}$ & - & - & - & - & - & - \\
\hline
\end{tabular}

Means followed by the same letter are not significantly different at $P<0.05$, when analyzed using Duncan's test of one way ANOVA.

Table 7. Effects of the culture broths of five species of marine-derived fungi at different concentrations on promotion of rice root elongation after 96 hours

\begin{tabular}{lccccccc}
\hline \multirow{2}{*}{ Treatment } & \multicolumn{7}{c}{ Root length (cm) at concentrations (g/ L) } \\
\cline { 2 - 8 } & 0 & 0.001 & 0.01 & 0.1 & 1 & 10 & 100 \\
\hline Emericella stellatus KUFA 0208 & - & $1.98^{\mathrm{g}}$ & $1.40^{\mathrm{n}}$ & $1.31^{\circ}$ & $0.96^{\mathrm{r}}$ & $0.39^{\mathrm{v}}$ & $0.13^{\mathrm{y}}$ \\
Neosartorya siamensis KUFA 0514 & - & $1.52^{\mathrm{j}}$ & $1.63^{\mathrm{i}}$ & $1.15^{\mathrm{p}}$ & $1.11^{\mathrm{q}}$ & $0.00^{\mathrm{z}}$ & $0.00^{\mathrm{z}}$ \\
Neosartorya spinosa KUFA 0528 & - & $1.48^{\mathrm{k}}$ & $1.44^{\mathrm{l}}$ & $1.42^{\mathrm{m}}$ & $0.53^{\mathrm{u}}$ & $0.54^{\mathrm{u}}$ & $0.21^{\mathrm{x}}$ \\
Trichoderma asperellum KUFA 0559 & - & $2.32^{\mathrm{d}}$ & $2.40^{\mathrm{b}}$ & $2.49^{\mathrm{a}}$ & $1.83^{\mathrm{h}}$ & $0.95^{\mathrm{r}}$ & $0.33^{\mathrm{w}}$ \\
Trichoderma harzianum KUFA 0631 & - & $0.90^{\mathrm{s}}$ & $2.33^{\mathrm{d}}$ & $2.35^{\mathrm{c}}$ & $2.23^{\mathrm{e}}$ & $0.60^{\mathrm{t}}$ & $0.00^{\mathrm{z}}$ \\
Negative control & $2.02^{\mathrm{f}}$ & - & - & - & - & - & - \\
\hline
\end{tabular}

Means followed by the same letter are not significantly different at $P<0.05$, when analyzed using Duncan's test of one way.

with chloroform exhibited antifungal effects against the growth of $A$. padwickii evidenced by the clear inhibition zones around the discs containing the fractions, which means the antibiosis compounds produced by this fungus were of low polarity and diluted well in petroleum ether or chloroform.

Emericella species are one of main bioactive compound producers in inhibition of pathogen growth. In this study, the crude extract of E. stellatus KUFA0208 also displayed potent antifungal activity by complete mycelial growth inhibition of A. padwickii, B. oryzae, P. oryzae and $R$. solani at $10 \mathrm{~g} / \mathrm{L}$ and $55 \%$ inhibition of $B$. oryzae at $1 \mathrm{~g} / \mathrm{L}$. The results in this study corresponding with previous studies which reported that the crude extracts of three Emericella species showed strong antagonistic activity against the mycelial growth of tested plant pathogenic fungi at $10 \mathrm{~g} /$ $\mathrm{L}$, causing $72-83 \%$ inhibition of $A$. brassicicola, $C$. capcisi, C. gloeosporioides and F. oxysporum. ${ }^{23}$ The crude extracts of $E$. rugulosa and $E$. nidulans isolated from soils displayed strong antifungal activity against $C$. gloeosporiodes and $F$. oxysporum f.sp. lycopersici with $\mathrm{ED}_{50}$ values 5.98 and $1000 \mu \mathrm{g} /$ $\mathrm{mL}$, respectively. ${ }^{39-41}$

The crude extracts of three species of marine Talaromyces were evaluated for their antifungal activity in this study, and it was found that the extracts of $T$. flavus KUFA 0119 and T. trachyspermus KUFA0304 displayed high antagonistic activity in the mycelial growth inhibition of rice pathogens whereas the extract of T. macrosporus KUFA 0135 showed low antagonistic activity against the pathogens' growth. Species of Talaromyces have been reported from various habitats including soil, plant and marine environments and many studies have reported their antagonistic activity against plant disease. For instance, the crude ethyl acetate extract of T. trachyspermus, which was isolated from the marine sponge Clathria reinwardtii obtained from a coral reef in Thailand, exhibited effective mycelial growth inhibition of Alternaria brassicicola, 
Collectrotrichum capsici, Helminthosporium maydis, Pythium aphanidermatum, Rhizoctonia solani and Sclerotium rolfsii with $\mathrm{IC}_{50}$ values ranging from 100-186 ppm and also displayed complete mycelial growth inhibition of all tested plant pathogenic fungi at a concentration of 10,000 ppm. ${ }^{26}$ Talaromyces tratensis KUFA 0091 exhibited effective inhibition of mycelial growth of Bipolaris oryzae, causing $40.89 \%$ inhibition using dual culture assay. In addition, the ethyl acetate crude extract of $T$. tratensis showed potent mycelial inhibition of $B$. oryzae at low concentration. Its crude extract and spore suspension had great effect against rice dirty panicle disease, reducing incidence by up to $60 \%$ under field conditions. ${ }^{21}$

However, the extracts of two marine Trichoderma showed low to moderate antifungal activity against rice pathogens in this study. The T. harzianum KUFA 0631 extract exerted 100\% inhibition on mycelial growth of $A$. padwickii and $R$. solani at $10 \mathrm{~g} / \mathrm{L}$ whereas both the $T$. asperellum KUFA 0559 and T. hamatum KUFA 0629 extracts

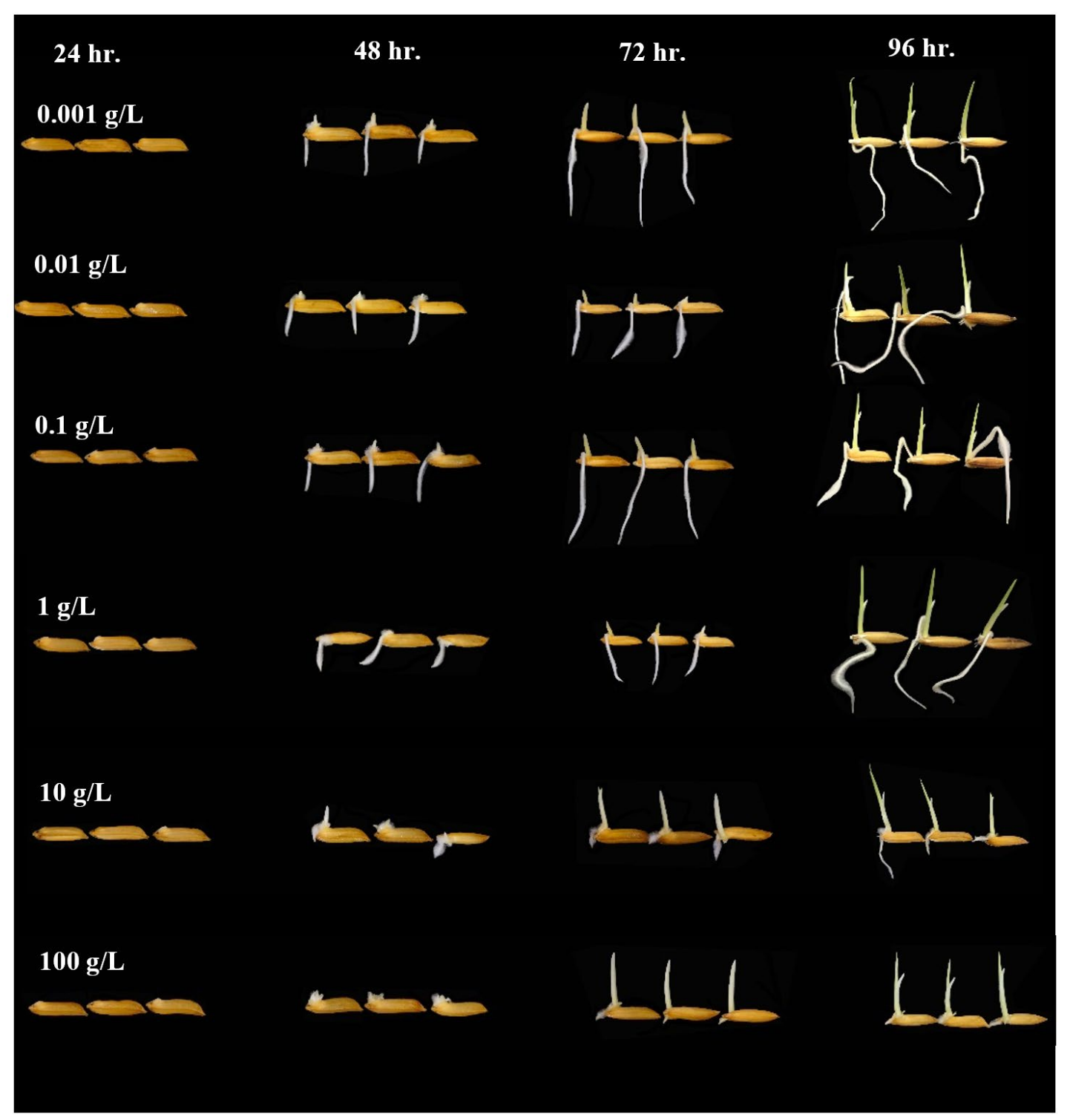

Fig. 3. Effect of T. asperellum KUFA 0559 culture broth at different concentrations on rice germination. 
exhibited complete inhibition on mycelial growth of $B$. oryzae, but they had low activity at low concentrations. These results correspond with a previous report of the antifungal effect of $T$. atroviride, which had the lowest activity against the olive pathogens, Phytopthora megasperma, $P$. inundata and Verticillium dahlia, when compared with others. ${ }^{42}$

Moreover, the marine fungi were tested for their rice growth promotion on rice var. KMDL105 and their production of IAA, which is a well-known plant growth hormone affecting plant cell elongation and cell division. ${ }^{43}$ Rice seedlings are susceptible to soil pathogens and easily infected by both pre and post-emergence pathogens in soil. The results in this study found that the treatment with T. asperellum KUFA 0559 and $T$. harzianum KUFA 0631 broths resulted in good rice growth promotion, enhancing rice shoot height and root length when compared with the untreated control. The results in this study correspond with previous studies which found that Trichoderma species exerted the plant growth stimulation in many crops when applied as seed or foliar treatments. For instance, seed treated with the formulated $T$. erinaceum improved the germination rate of rice and enhanced vigour by improving chlorophyll content and resulted in high rice yield..$^{44}$ Trichoderma harzianum-bioprimed rice was reported to enhance rice growth in droughtstressed soils by triggering various respond mechanisms via many pathways. ${ }^{45}$ Moreover,

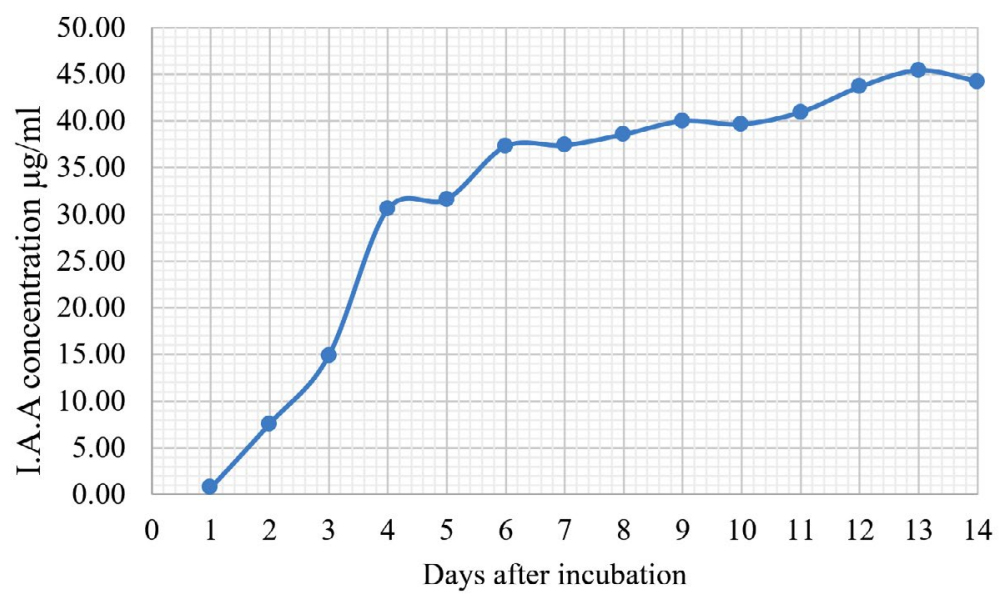

Fig. 4. Indole acetic acid production by T. asperellum KUFA 0559.

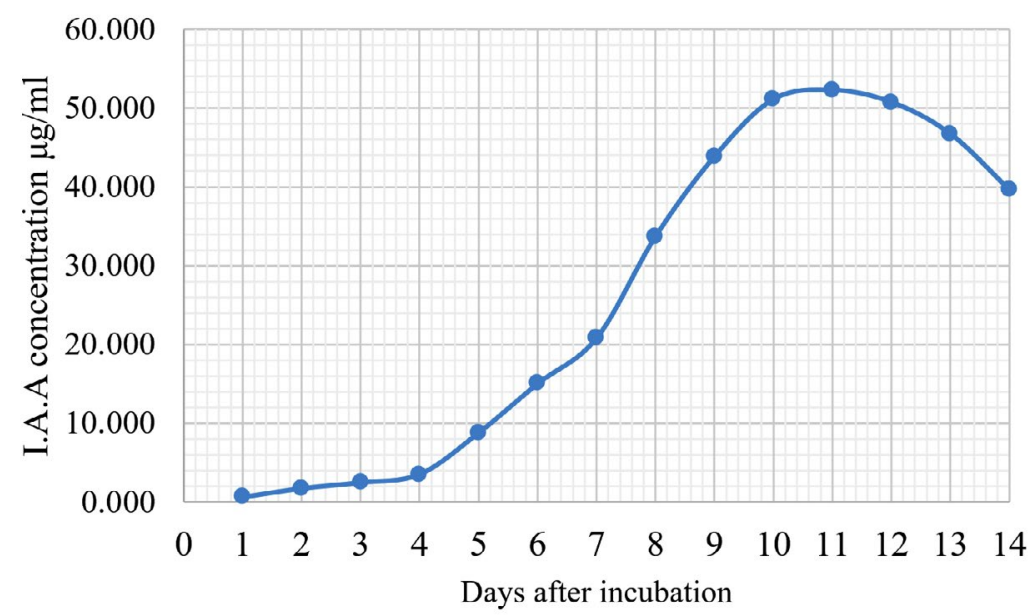

Fig. 5. Indole acetic acid production by Trichoderma harzianum KUFA 0631. 
many Trichoderma species were reported as a potent producers of IAA and enzymes which enhanced plant tolerance to biotic and abiotic stress. Trichoderma longibrachiatum T6 (TL-6) significantly improved the growth of wheat and enhanced wheat tolerance to $\mathrm{NaCl}$ stress by reducing the transcriptional level of ethylene synthesis genes expression, and increasing IAA production gene expression. ${ }^{46}$ Trichoderma harzianum strain T-A66 had a strong promotion effect on bitter gourd seedlings growth and induced disease resistance against bitter gourd wilt caused by F. oxysporum, by inducing IAA, quick $\mathrm{H}_{2} \mathrm{O}_{2}$ bursts and callose deposition, as well as increasing antioxidant enzyme activities and phenolic compound content. ${ }^{47}$ Treatment with
T. virens stimulated mungbean seedling growth, increasing total biomass, root weight, and root length as well as improving chlorophyll content and IAA-synthase in leaves and roots. ${ }^{48}$

Results from this study indicated that the marine-derived fungi tested had potent antagonistic activities against rice pathogens via many antagonistic mechanisms including antibiosis production resulting in potent mycelial growth inhibition of rice pathogens and plant growth promotion. The crude extract of marine fungi, $N$. siamensis KUFA0514 had promising antifungal activity against rice pathogen growth by producing low-polarity antifungal compounds which dissolved well in petroleum-ether or chloroform. Trichoderma asperellum KUFA

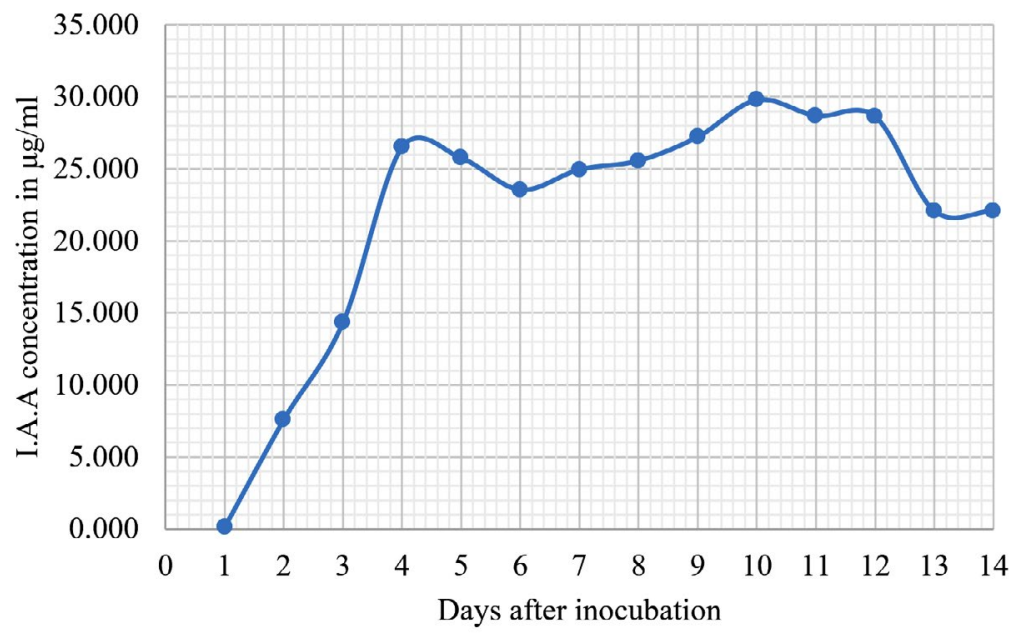

Fig. 6. Indole acetic acid production by Neosartorya siamensis KUFA0514.

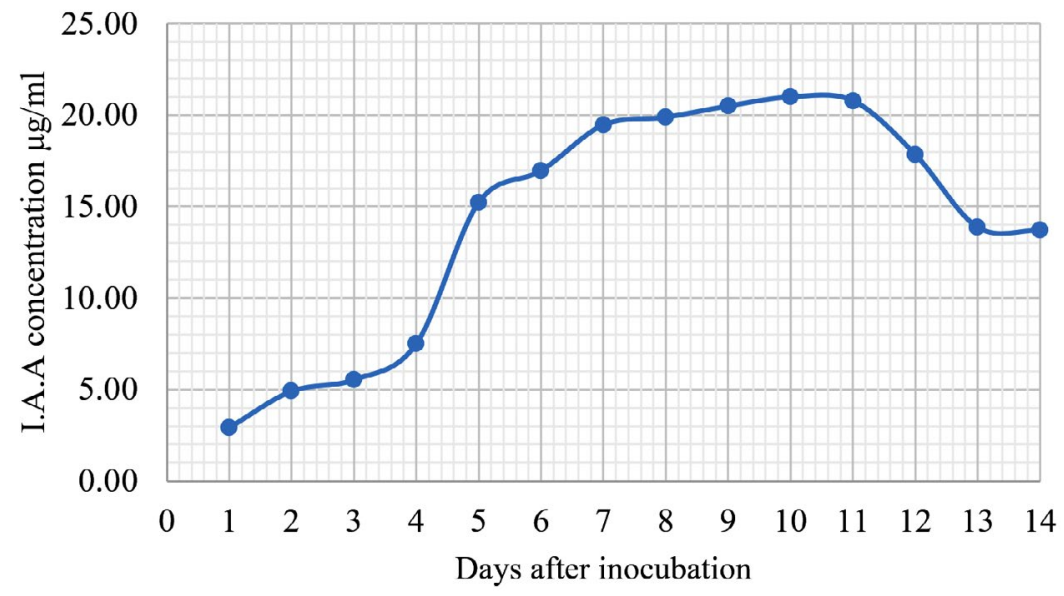

Fig. 7. Indole acetic acid production by Neosartorya spinosa KUFA 0528. 


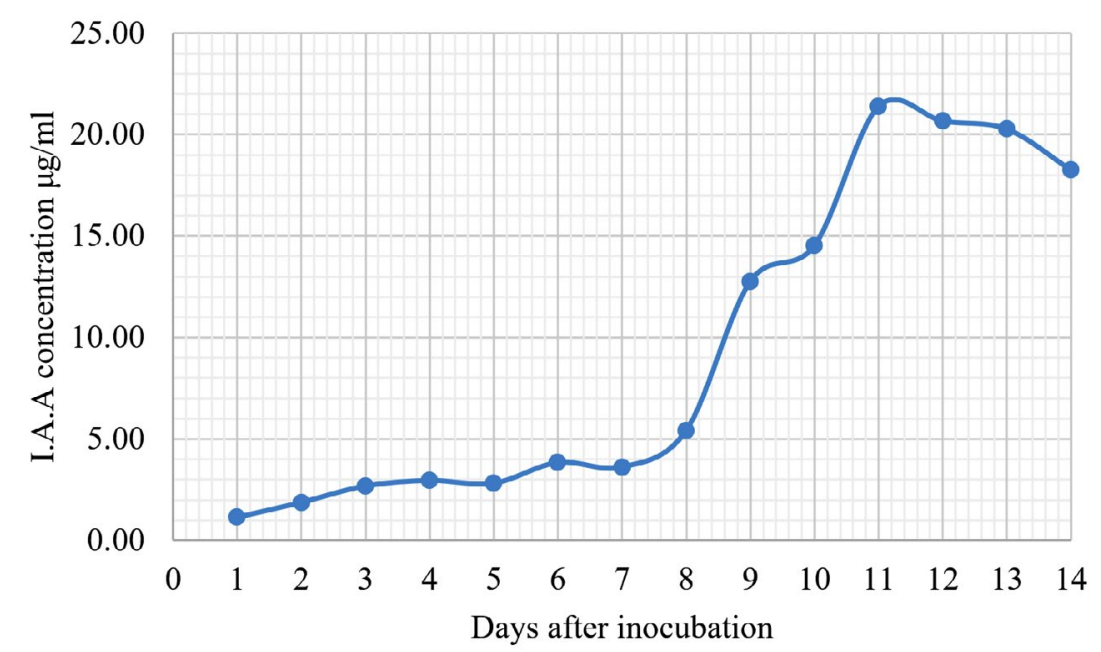

Fig. 8. Indole acetic acid production by Emericella stellatus KUFA0208.

0559 broth displayed great growth stimulation in increasing on rice root and shoot lengths. Both marine fungi may have potential for development as novel biocontrol agents in rice disease management.

\section{ACKNOWLEDGMENTS}

The authors would like to thank the Graduate School, Kasetsart University and the Kasetsart University Research Development Institute (KURDI), Bangkok, Thailand for financial support for this project.

\section{CONFLICT OF INTEREST}

The authors declare that there is no conflict of interest.

\section{AUTHORS' CONTRIBUTION}

All authors listed have made a substantial, direct and intellectual contribution to the work, and approved it for publication.

\section{FUNDING}

This study was supported by the Kasetsart University Research Development Institute (KURDI), Bangkok, Thailand (Grant number PK157026).

\section{DATA AVAILABILITY}

The datasets generated during and/or analysed during the current study are available from the corresponding author on reasonable request.

\section{ETHICS STATEMENT}

This article does not contain any studies with human participants or animals performed by any of the authors.

\section{REFERENCES}

1. Chakraborty M, Mahmud NU, Gupta DR, Tareq FS, Shin $\mathrm{HJ}$, Islam T. Inhibitory effects of linear lipopeptides from a marine Bacillus subtilis on the wheat blast fungus Magnaporthe oryzae Triticum. Front Microbiol. 2020;11:665. doi: 10.3389/fmicb.2020.00665

2. Duraes F, Szemeredi N, Kumla D, et al. Metabolites from marine-derived fungi as potential antimicrobial adjuvants. Mar Drugs. 2021;19(9):475. doi: 10.3390/ md19090475

3. Ghoran SH, Kijjoa A. Marine-derived compounds with anti-alzheimer's disease activities. Mar Drugs. 2021;19(8):410. doi: 10.3390/md19080410

4. Li $X$, Zhao H, Chen X. Screening of marine bioactive antimicrobial compounds for plant pathogens. Mar Drugs. 2021;19(2):69. doi: 10.3390/md19020069.

5. Kang HK, Seo CH, Park Y. Marine peptides and their anti-infective activities. Mar Drugs. 2015;13(1):618654. doi: 10.3390/md13010618

6. Castronovo LM, Vassallo A, Mengoni A, et al. Medicinal plants and their bacterial microbiota: a review on Antimicrobial Compounds Production for Plant and Human Health. Pathogens. 2021;10(2):106. doi: 10.3390/pathogens10020106

7. Liu L, Zheng Y-Y, Shao C-L, Wang C-Y. Metabolites from marine invertebrates and their symbiotic microorganisms: molecular diversity discovery, mining, and application. Mar Life Sci Technol. 2019;1(1):60-94. doi: 10.1007/s42995-019-00021-2 
8. Dethoup T, Gomes NGM, Chaopongpang S, Kijjoa A. Aspergillus similanensis sp.nov. from a marine sponge in Thailand. Mycotaxon. 2016;131(1):7-15. doi: $10.5248 / 131.7$

9. de Oliveira BFR, Carr CM, Dobson ADW, Laport MS. Harnessing the sponge microbiome for industrial biocatalysts. Appl Microbiol Biotechnol. 2020;104(19):8131-8154. doi: 10.1007/s00253-02010817-3

10. Kaewkrajay C, Putchakarn S, Limtong S. Cultivable yeasts associated with marine sponges in the Gulf of Thailand, South China Sea. Antonie van Leeuwenhoek. 2021;114(3):253-274. doi: 10.1007/s10482-02101518-6

11. Kohlmeyer J, Kohlmeyer E. Marine mycology: the higher fungi. Academic Press, London, England. 1979

12. Pang K-L, Overy DP, Jones EBG, et al. 'Marine fungi' and 'marine-derived fungi' in natural product chemistry research: toward a new consensual definition. Fungal Biol Rev. 2016;30(4):163-175. doi: 10.1016/j. fbr.2016.08.001

13. Carroll AR, Copp BR, Davis RA, Keyzers RA, Prinsep MR. Marine natural products. Nat Prod Rep. 2021;38(2):362-413. doi: 10.1039/DONP00089B

14. Zhang $\mathrm{H}$, Zou J, Yan $\mathrm{X}$, et al. Marine-derived macrolides 1990-2020: an overview of chemical and biological diversity. Mar Drugs. 2021;19(4):180. doi: 10.3390/ md19040180

15. $\mathrm{X} u \mathrm{~T}-\mathrm{C}, \mathrm{Lu} \mathrm{Y}-\mathrm{H}, \mathrm{W}$ Wang J-F, et al. Bioactive secondary metabolites of the genus Diaporthe and anamorph Phomopsis from terrestrial and marine habitats and endophytes: 2010-2019. Microorganisms. 2021;9(2):217. doi: 10.3390/microorganisms9020217

16. Notarte $\mathrm{KI}, \mathrm{Nakao} \mathrm{Y}$, Yaguchi T, Bungihan M, Suganuma K, Dela Cruz TE. Trypanocidal activity, cytotoxicity and histone modifications induced by malformin $\mathrm{A} 1$ isolated from the marine-derived fungus Aspergillus tubingensis IFM 63452. Mycosphere. 2017;8(1):111120. doi: $10.5943 /$ mycosphere/8/1/10

17. Notarte KI, Yaguchi T, Suganuma K, dela Cruz TE. Antibacterial, cytotoxic and trypanocidal activities of marine-derived fungi isolated from Philippine macroalgae and seagrasses. Acta Bot Croat. 2018;77(2):141-151. doi: 10.2478/botcro-2018-0016

18. dela Cruz TEE, Notarte KIR, Apurillo CCS, Tarman K, Bungihan ME. Chapter 4 - Biomining fungal endophytes from tropical plants and seaweeds for drug discovery. Biodiversity and Biomedicine. 2020:51-62. doi: 10.1016/B978-0-12-819541-3.00004-9

19. Machado FP, Kumla D, Pereira JA, et al. Prenylated phenylbutyrolactones from cultures of a marine sponge-associated fungus Aspergillus flavipes KUFA1152. Phytochemistry. 2021;185:112709. doi: 10.1016/j.phytochem.2021.112709

20. de Sa JDM, Pereira JA, Dethoup T, et al. Anthraquinones, diphenyl ethers, and their derivatives from the culture of the marine sponge-associated fungus Neosartorya spinosa KUFA 1047. Mar Drugs. 2021;19(8):457. doi: 10.3390/md19080457

21. Dethoup T, Kaewsalong N, Songkumorn P, Jantasorn A. Potential of a marine-derived species, Talaromyces tratensis KUFA 0091 against rice diseases. Biol Control.
2018;119:1-6. doi: 10.1016/j.biocontrol.2017.11.008

22. Chalearmsrimuang T, Ismail SI, Mazlan N, Suasa-ard $\mathrm{S}$, Dethoup T. Marine-derived fungi: a promising source of halotolerant biological control agents against plant pathogenic fungi. J Pure Appl Microbiol. 2019;13(1):209-223. doi: 10.22207/JPAM.13.1.22

23. Kokkrua S, Ismail SI, Mazlan N, Dethoup T. Efficacy of berberine in controlling foliar rice diseases. Eur J Plant Pathol. 2020;156(1):147-158. doi: 10.1007/s10658019-01871-3

24. Eakjamnong W, Keawsalong N, Dethoup T. Novel ready-to-use dry powder formulation of Talaromyces tratensis KUFA0091 to control dirty panicle disease in rice. Biol Control. 2021;152:104454. doi: 10.1016/j. biocontrol.2020.104454

25. Suasa-ard S, Eakjamnong W, Dethoup T. A novel biological control agent against postharvest mango disease caused by Lasiodioplodia theobromae. Eur J Plant Pathol. 2019;155(2):583-592. doi: 10.1007/ s10658-019-01794-z

26. Dethoup T, Kumla D, Kijjoa A. Mycocidal activity of crude extracts of marine-derived beneficial fungi against plant pathogenic fungi. J Biopesticides. 2015;8(2):107-115.

27. Gal-Hemed I, Atanasova L, Komon-Zelazowska M, Druzhinina IS, Viterbo A, Yarden O. Marine isolates of Trichoderma spp. As potential halotolerant agents of biological control for arid-zone agriculture. Appl Environ Microbiol. 2011;77(15):5100-5109. doi: 10.1128/AEM.00541-11

28. Ngo MT, Nguyen MV, Han JW, Park MS, Kim H, Choi GJ. In Vitro and In Vivo antifungal activity of sorbicillinoids produced by Trichoderma longibrachiatum. J Fungi. 2021;7(6):428. doi: 10.3390/jof7060428

29. Degani O, Dor S. Trichoderma biological control to protect sensitive maize hybrids against late wilt disease in the field. J Fungi. 2021;7(4):315. doi: 10.3390/ jof7040315

30. Raymaekers K, Ponet L, Holtappels D, Berckmans B, Cammue BPA. Screening for novel biocontrol agents applicable in plant disease management - A review. Biol Control. 2020;144:104240. doi: 10.1016/j. biocontrol.2020.104240

31. Xin W, Mao Y, Lu F, et al. In vitro fungicidal activity and in planta control efficacy of coumoxystrobin against Magnaporthe oryzae. Pestic Biochem Phys. 2020;162:78-85. doi: 10.1016/j.pestbp.2019.09.004

32. Wang $Z$, Dai T, Peng $Q$, et al. Bioactivity of the novel fungicide SYP-14288 against plant pathogens and the study of its mode of action based on untargeted metabolomics. Plant Dis. 2020;104(8):2086-2094. doi: 10.1094/PDIS-01-20-0142-RE

33. Murray MG, Thompson WF. Rapid isolation of high molecular weight plant DNA. Nucleic Acids Res. 1980;8(19):4321-4326. doi: 10.1093/nar/8.19.4321

34. White TJ, Bruns T, Lee S, Taylor J. Amplification and direct sequencing of fungal ribosomal RNA genes for phylogenetics. In: Innis MA, Gelfand DH, Sninsky JJ, White TJ (eds.). PCR protocols: a guide to methods and applications. Academic Press, New York, USA. Murray and Thompson method. 1990:315-322. doi: 10.1016/ B978-0-12-372180-8.50042-1 
35. Bhagobaty RK, Joshi SR. Promotion of seed germination of green gram and chick pea by Penicillium verruculosum RS7PF, a root endophytic fungus of Potentilla fulgens L. Advanced Biotech. 2009.

36. Eamvijarn A, Manoch L, Chamswarng C. Aspergillus siamensis sp. nov. from soil in Thailand. Mycoscience. 2013;54(6):401-405. doi: 10.1016/j.myc.2013.01.005

37. Buttachon S, Chandrapatya A, Manoch L, et al. Sartorymensin, a new indole alkaloid, and new analogues of tryptoquivaline and fiscalins produced by Neosartorya siamensis (KUFC 6349). Tetrahedron. 2012;68(15):3253-3262. doi: 10.1016/j. tet.2012.02.024

38. Prata-Sena M, Ramos AA, Buttachon S, et al. Cytotoxic activity of secondary metabolites from marine-derived fungus Neosartorya siamensis in human cancer cells. Phytother Res. 2016;30(11):1862-1871. doi: 10.1002/ ptr.5696

39. Talubnak C, Soythong K. Biological control of vanilla anthracnose using Emericella nidulans. J Agri Technol. 2012;6:47-55.

40. Sibounnavong P, Chareonporn C, Kanokmedhakul S, Soytong K. Antifungal metabolites from antagonistic fungi used to control tomato wilt fungus Fusarium oxysporum f.sp. Iycopersici. Afr J Biotechnol. 2011;10(85):19714-722. doi: 10.5897/AJB11.3343

41. Kumsorn W. Diversity of Emericella species from soil and in vitro efficacy against plant pathogenic fungi. M.Sc. thesis, Faculty of Agriculture, Kasetsart University. Bangkok, Thailand. 2013.

42. Lozano-Tovar MD, Ortiz-Urquiza A, Garrido-Jurado I, Trapero-Casas A, Quesada-Moraga E. Assessment of entomopathogenic fungi and their extracts against a soil-dwelling pest and soil-borne pathogens of olive.
Biol Control. 2013;67(3):409-420. doi: 10.1016/j. biocontrol.2013.09.006

43. Saechow S, Thammasittirong A, Kittakoop P, Prachya $\mathrm{S}$, Thammasittirong SN-R. Antagonistic activity against dirty panicle rice fungal pathogens and plant growthpromoting activity of Bacillus amyloliquefaciens BAS23. J Microbiol Biotechnol. 2018;28(9):1527-1535. doi: $10.4014 / j m b .1804 .04025$

44. Swain H, Adak T, Mukherjee AK, et al. Novel Trichoderma strains isolated from tree barks as potential biocontrol agents and biofertilizers for direct seeded rice. Microbiol Res. 2018;214:83-90. doi: 10.1016/j.micres.2018.05.015

45. Bashyal BM, Parmar P, Zaidi NW, Aggarwal R. Molecular programming of drought-challenged Trichoderma harzianum-bioprimed rice (Oryza sativa L.). Front Microbiol. 2021. doi: 10.3389/fmicb.2021.655165

46. Zhang S, Gan Y, Xu B. Mechanisms of the IAA and ACC-deaminase producing strain of Trichoderma longibrachiatum T6 in enhancing wheat seedling tolerance to $\mathrm{NaCl}$ stress. BMC Plant Biology. 2019;19(1):22. doi: 10.1186/s12870-018-1618-5

47. Zhang F, Liu C, Wang Y, et al. Biological characteristic and biocontrol mechanism of Trichoderma harzianum T-A66 against bitter gourd wilt caused by Fusarium oxysporum. J Plant Pathol. 2020;102:1107-1120. doi: 10.1007/s42161-020-00573-8

48. Inayati A, Sulistyowati L, Aini LQ, Yusnawan E. Trichoderma virens-Tv4 enhances growth promoter and plant defense-related enzymes of mungbean (Vigna radiata) against soil-borne pathogen Rhizoctonia solani. Biodiversitas. 2020;21:2410-2419. doi: 10.13057/biodiv/d210611 